\title{
Categorization and Sorting for Waste Management Dupre Mickael*
}

Doctor in Social Psychology-Research Associate, European University of Brittany, University of South Brittany, France

"Corresponding author: Dupre Mickael, Doctor in Social Psychology-Research Associate, University of South Brittany, Center for Research in Psychology, Cognition and Communication (CRPCC)-Ergonomics Laboratory Systems, Information Processing and Behavior (Lestic), Campus Tohannic, Rue Yves Mainguy-56 000 Vannes, France, Tel: 06629973 77; E-mail: mickael_dupre@yahoo.fr

Received date: June 14, 2016, Accepted date: June 23, 2016, Published date: June 30, 2016

Copyright: (C) 2016 Mickael D. This is an open-access article distributed under the terms of the Creative Commons Attribution License, which permits unrestricted use, distribution, and reproduction in any medium, provided the original author and source are credited.

\section{Abstract}

The success of the waste management policy is based on good sorting practice by the largest number of citizen. There are on the French territory more than 300 devices sorting instructions, collection or different labels. Sorting instructions depend technologies deployed in sorting and recycling management. Sorting instructions are essentially defined by technological factors. The users have to learn and respect the categorization of waste defined by the managers. The national average is $17 \%$ of collections which are refused entry sorting centers due to poor sorting. The goal of our study is to explore the link between the sorting instructions and the categorization process. For this, 191 individuals did a categorization task of several wastes. Analysis of the data shows that people use differents criterias of classification. More specifically, more natural categories such as material waste or use depending on the object are most frequently used by individuals. The results also show that the categorization according to the criteria of recyclability increases with knowledge sorting instructions and frequency of practice sorting.
\end{abstract}

Keywords: Environment; Institutional arrangements; Psychology; Categorization; Sorting instruction

\section{Introduction}

With the oil shocks of the 1970s, governments and industry are aware of the finiteness of raw material deposits. The French Law of 15 July 1975 amends legislation on waste management which hitherto was based on the order of Villers-Coteret written in 1539 and transfers responsibility Consumer Waste treatment in the public administration. If the Act of 15 July 1975 up recycling as the main objective in terms of waste management, it was not until the Act of 13 July 1992 to see the OECD created the Extended Producer Responsibility. EPR provides that companies, as producers of packaging, offering a solution to consumers to manage their waste non-polluting. Recycling and collection into place gradually over almost all the territory. The first year, the household waste recycling rate is $18 \%$, in 1999 it reached $41 \%$ in 2004 and $55 \%$ in 2011 , rising to $67 \%$. In $2012,99.4 \%$ of the population has access to a collection device whose waste is routed to the 257 sorting centers nationwide [1].

Over the years, waste sorting has become the most widespread ecological gesture in the population and is systematically for $66 \%$ of the population (ibid). On average, each inhabitant produces annually 45 kilos of waste that is recycled and 353 kilos which leave the garbage, 86 kilos that are household packaging. On nearly a million tons of plastic packaging placed on the market annually, only 235000 are thus recycled.

In 2012, the National sorting refusal rate was $17 \%$ (ibid). Not only refused the collection is not recycled and goes to landfill or incineration, but also significantly increases the management cost. A cargo refused entry of the sorting center and redirected towards the garbage management circuit has a price three times higher for the taxpayer than if it had been initially treated from household waste. Two major factors affect the sorting refusal rate. On the one hand, it is higher in urbanized areas and dense city. On the other hand, territories that have established sorting instructions according to which paper and packaging is mixed also face more rejection than sorting centers which separately receive paper and packaging. Different organizations collecting indeed exist on French territory and no fewer than 300 sorting instructions devices, or collection of different Safety (ibid.). Responsibility for the collection depends on the local authorities and color codes are for example not all harmonized France. "The lack of homogeneity of the night to device effective national information campaigns and is confusing for the citizen" [2]. Also, the Grenelle law provides for harmonization of devices sorting instructions by $1^{\text {st }}$ January 2015.

In this perspective, studies conducted in 2009 by Eco-Packaging and ADEME on the extension of sorting instructions plastic household packaging, beyond the few bottles and flasks, have shown the potential value that could have such measurement (ibid.). An experiment on the extension of instructions is conducted until December 2013 with 3.7 million people spread over 51 communities. The first results conclude that $13 \%$ more tonnage on average by sorting and $2 \%$ refused access to sorting centers [1]. Also, it seems that these rules are better understood by consumers and that sort of gesture is seen as simpler (ibid., P. 13). Indeed, today, only bottles and PET bottles and HDPE can be recycled at national level. Other types of plastic are not. Sorting instructions recommend throwing in stores dedicated to the collection. On most of the territory, the specifications are based on the distribution of waste into three streams: glass bottles and jars are to be filed voluntary contribution of specific points. All paper/cardboard, steel and aluminum, and plastic bottles and flasks are supported by separate collection. Other waste is to throw from household waste. Another target is based on the management of four flow by separating paper from other waste recycled. These instructions are dependent on technical aspects such as sorting technologies sorting center, recycling technologies, upgrading existing networks, the profitability of recycling of materials, etc. Also, "the problem of sorting and recycling of waste takes even less account of households it is, in fact, almost exclusively 
linked to economic and industrial issues" [3]. Putting together the metal, paper and some plastics seems a priori not intuitive. For example, according to the most common set in the country, a tin can and a plastic bottle of liquid cream are thrown into the same bin as the cream will meanwhile in another container. Yet these two waste seem a priori share more similarities. Sorting instructions distinguish two categories of waste: recyclable and non - recyclable. Also, it seems relevant to question these instructions with the theories of categorization.

\section{Categorization}

Sorting instructions differ in fact several categories of waste. There are specific waste bin each color. The user of the collection service has to learn the rules established by the local authority and to endorse. Besides the sorting of glass and optionally organic waste, the individual must create two categories of waste including those he throws among the garbage and those that throw from the collection. To do this, the individual goes through a categorization process. In the introduction to the study of thought, Bruner et al. [4] define this process as an act of grouping different elements but considered equivalent to organize classes in objects, events and people that appear in our lives every day. The categorization simplifies the environment by making them more easily and quickly stimuli understandable and manageable [5]. She quickly identifies the new elements in treating them as objects already known and that the individual judge as similar [6]. Perceptions may well rest on "preformed categories" [6] that make them predictable events. The categorization accompanies and therefore also helps in decision making by allowing the individual to predict events and appropriate behavior from re-known properties of the category of the object encountered. Indeed, by integrating a category, the item is given the characteristics belonging to its allocation category [7]. It will then include features and properties necessary to define and differentiate the category of categories available [8]. However, these functions can be false. The element can be transferred traits and properties, although belonging to his assignment category does not belong to him. For example, if the individual categorizes a plastic bag like a plastic packaging, it may assign the characteristic recyclability he attributed this trait to the category of plastic waste. In this case, with the sorting instructions "classic", the transfer of ownership has led the individual to a false attribution.

These properties recognized the elements of a class also allow the integration of new elements. The individual confronts in fact the properties of the object attributes of the various existing categories in its register. Several theories have proposed models of the categorization process $[9,10]$. The prototype $[11,12]$ model envisages that the category is organized around an abstract model called prototype. If the object sharing considered sufficient similarities with the prototype of a class, it can be integrated with it. On the contrary, if it strays too far from the prototype, it does not belong to the category known. The model of the copy $[13,14]$ is based on the principle of a remote object representative of the category. However, unlike the prototype can be an abstract representation, the copy is the actual element which for the individual, best embodies its membership category. A final model, inherited from connectionism [15] apprehends categories as dependent matrices interconnected networks traits and properties. Also, several factors affect the categorization that the individual elements will be encountered. It varies in fact based on personal beliefs [16], perception of the environment [17], the mental context of the individual, the salience of object properties [18] or the environmental context [9].
Depending on the context, individuals would choose so consciously or unconsciously for one model to categorize the directory entry.

The effect of context on the categorization process particularly raises questions. Indeed, the categories are mobilized into action and according to some authors, the process of allocating properties would be directly dependent on the context and the individual's goals [19]. The activation context of the category would saliency or muted for the class and thus the perceived similarity between the element to categorize and category [20]. The context therefore actively participate in the assignment of the process element in a category by making more or less relevant characteristics of the one and the other. From this perspective, the categories would be circumstantial constructions and would therefore be highly variable depending on situations [21]. Common psychological essentialism [14] and the naive theories $[22,23]$ defend as for them the idea that the categories are based on a conceptual content not subject to the effects contexts. According to these theories, the concepts are thus the organizing principles of the environment and in this sense, represent the environmental structure [24]. In other words, the knowledge held by individuals about a subject are only beliefs based on perception and not knowledge of what they really are [25].

Also, according to this definition, the categories are only slightly subject to the effects of context. These concepts would be stored in sustainably memory as they reflect our knowledge of the world. In a situation, some concepts are primarily activated, however, the activation context does not undermine the stability of the concept. Several experimental results support this hypothesis [26]. For example, Gaillard and Urdapilleta [27] asked individuals to categorize a list of food that was presented to them. They found that the clusters were very stable from one session to another. The authors also asked participants to describe the properties of food. They observed that produced descriptions vary in them between sessions. These results highlight and stability and flexibility of the categories. Processing information from a complex and moving indeed requires individuals that categories are not only stable to maintain a certain consistency in their perception of the world, but also flexible to accommodate the widest variety situations and changes that may occur [28].

To capture the stable elements of the categories, the preferred method is to ask the participant to classify according to criteria of their choice, the elements presented to him [18]. In this exercise, the individual must produce common properties between objects to organize them into categories. Several classifications are possible depending on the classification or criteria it retains. This method of observation is one that allows better control of context effects and the inter-subject variations [29]. In addition, the verbalization of categories and classification criteria used to obtain the decision rules, the logical criteria of the participant [30]. The classification task also offers the advantage of allowing to distinguish people based on their mental representations. For example, Medin et al. [31] showed that on a classification task of 48 different trees, landscape and novices have not achieved the same groupings. The first resorted to the criteria of grouping requiring a high level of knowledge on the field in question while the familiarity of trees guided the classification performed by novices. Moreover, all items and categories are also not treated the same way during categorization. Indeed, natural and manufactured categories are distinguished in fact quite clearly [32]. The natural elements (animals, plants, etc.) tend to be classified as perceptive and taxonomic characteristics (color, shape, size, etc.) while the artifacts are classified by scripts related to their function $[33,34]$ or goal [35]. 
Page 3 of 7

When a new item is assigned to a category, the individual may wish to test categorization. This can be done by questioning the consensus in this case which the individual seeks the views of other individuals, he considers as peers, to ensure that its decision is shared . A second method is based on a " sanity check " that the individual would assess the compatibility of its assessment with its past beliefs and experiences. The individual may use a ultimate criterion that qualifies or disqualifies the item to his assignment to a category. Finally, intuition can also intervene in the process validation of categorization.

\section{Problematic}

The sorting instructions distinguish User two waste categories: those to throw in the garbage refuse and those to throw in the trash for curbside recycling. These two categories are defined according to several mainly technical and economic factors. For example, only the plastic waste having a bottle shape are destined for recycling. Indeed, on one hand, these wastes are numerous and relatively large volume, which is a large amount of raw material. Moreover, their shape makes them easy to grasp the sorting center. Finally, plastics forming other packaging is not a chemical composition of sufficiently good quality to be recycled profitably in the current state of recycling facilities. The paper envelopes with a plastic window to show them the evolutionary aspect of the instructions. Indeed, initially, these envelopes were, according to the instructions, be disposed of with household waste. The set has changed and the envelopes are now destined for recycling. This set is thanks to technological advances that now separates the sorting center both materials of this waste. These examples illustrate the ad hoc dimension of sorting instructions. However, although the categories recyclable/non recyclable are defined by recycling professionals, they are for the user who needs to better internalize this categorization. This is likely to confront other existing categories, and perhaps more natural. Indeed, waste can share these characteristics that distinguish them from other waste: hollow and flat, dirty, dry, food and non-food, etc. These characteristics can lead the individual to categorizations might compete or interfere categorization by sorting instructions. Also, we will try to see how the categories defined by the sorting instructions are active in the individual. Specifically, we will investigate whether the categorization recyclable non recyclable Vs dominant in perceptual processes or if other categories are necessary to the perception of individuals.

\section{Experimentation}

\section{Population and sample}

Our study was conducted in a population residing in the territory of a large urban community in western France. For our study, we therefore considered the existing sorting instructions on this territory.
All participants resided in the country for at least two years. The sample consisted of 191 individuals including 98 men and 93 women with an average age of 29.7 years $(\sigma=3.4)$. All participants were recruited in the street.

\section{Measures}

We defined a primary dependent variable was the waste categorization criteria. We also measured exploratory purpose, two secondary variables : the level of understanding of sorting instructions and self-reported frequency sorting practice.

\section{Protocol}

To measure our variables, we designed a questionnaire. Participants had to respond and successively to a categorization task, an assessment of knowledge of sorting instructions, and measurement of the practice of self-reported frequency of sorting. Some information about the identity of the participant were collected at the end of the questionnaire.

\section{Categorization}

We designed a classification task. Participants were asked to identify an intruder to choose from five waste presented to them. They also had to say according to what (s) standard (s), the designated waste was an intruder.

For this, we selected a list of fifty waste among whom were the most common and waste subject of the most common sorting errors. These waste fifty, twenty-five were supported by the collection and twentyfive were not.

From these fifty waste, we designed ten lists five waste. These lists are presented in Table 1. In five lists were four waste unsupported and waste covered by selective collection. In the other five lists, there were four waste supported and unsupported by curbside waste. In each list were therefore an intruder on the balance of support by selective collection.

We designed five of the ten lists with categorization criteria previously identified. A preliminary survey of 17 people in the form of semi-structured interviews identified four criteria by which individuals are particularly susceptible to classify waste groups. This is the constitution of material, form of the waste, the use of function of the object, the place of its use and the theme or symbolic universe to which it may be associated. We designed five lists in which waste shared all but one one of these characteristics (List A). The five other series were designed randomly by lot waste, by ensuring, however, that in each list was an intruder in terms of support for selective collection (List B).

\begin{tabular}{|l|l|l|l|}
\hline \multicolumn{2}{|l|}{ series } & $\mathbf{4}$ recyclables / 1 non-recyclable waste & $\mathbf{4}$ recyclables / 1 recyclable waste \\
\hline $\begin{array}{l}\text { Categorized a priori } \\
(\text { List A) }\end{array}$ & 1 Material & $\begin{array}{l}\text { a jam jar lid, a metal tea box * A cup plastic } \\
\text { coffee, a staple, an aluminum tray }\end{array}$ & \\
\cline { 2 - 4 } & 2 Shape & $\begin{array}{l}\text { a plastic shopping bag, paper shopping bag * } \\
\text { bag in burlap, a freezer bag, a beer cap }\end{array}$ & $\begin{array}{l}\text { a weedkiller container, a fly swatter **, a newspaper, aerosol } \\
\text { insecticide, pesticide A cardboard }\end{array}$ \\
\cline { 2 - 4 } & 3 Usage & & \\
\hline
\end{tabular}




\begin{tabular}{|c|c|c|c|}
\hline & 4 Lieu & & $\begin{array}{l}\text { a bottle of shower gel, a hair lacquer spray, a toothpaste tube }{ }^{* *} \text {, a } \\
\text { book, a bottle of conditioner }\end{array}$ \\
\hline & 5 Theme & $\begin{array}{l}\text { a toy * carton a Christmas tree ball, gift } \\
\text { paper, a tray of polystyrene sausage, a Santa } \\
\text { figurine plaster }\end{array}$ & \\
\hline \multirow[t]{5}{*}{ Random (list B) } & 6 & $\begin{array}{l}\text { a deodorant aerosol *, a metal tube of } \\
\text { mayonnaise, a plastic ice pot, a toothbrush, a } \\
\text { cotton swab }\end{array}$ & \\
\hline & 7 & $\begin{array}{l}\text { a box of canned ratatouille }{ }^{*} \text { From aluminum } \\
\text { foil, a tray of bacon, a bag of pasta, a paper } \\
\text { candy bar }\end{array}$ & \\
\hline & 8 & & $\begin{array}{l}\text { a water bottle plastic yoghurt pot }{ }^{* *} \text {, a tin of ravioli, a cereal box } \\
\text { cardboard, a brick soup }\end{array}$ \\
\hline & 9 & & $\begin{array}{l}\text { a pot of butter Shea }{ }^{* *} \text {, a bleach bottle, an envelope, a wine } \\
\text { cubitainer a shine spray }\end{array}$ \\
\hline & 10 & & $\begin{array}{l}\text { a carton of milk, a bottle of drinking yoghurt, a laundry cardboard, a } \\
\text { brick béchamel, a carton softener }{ }^{* *}\end{array}$ \\
\hline
\end{tabular}

Table 1: Lists of wastes used in the categorization task. ${ }^{*}$ waste recyclable, ${ }^{* *}$ waste non recyclable.

The waste was in the form of pictures with a series of five pictures waste board (Figure 1). The waste was clearly identifiable in the pictures. To avoid a possible order effect before each award, the boards were mixed and were thus presented in random order. In addition, we have also fop vary the order of the waste in each list. All three experimenters were indeed different orders of appearance of waste within each list.

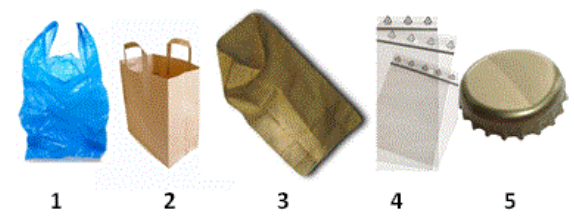

Figure 1: Example of a board used.

For this task, the instruction provided to participants was: "I will present ten lists five waste. For each of these lists, you appoint somebody from you is an intruder and say for what (s) reason (s). There are no right or wrong answers! "

As an illustration of the set, a neutral example was presented to the participants before starting the task. It was a series of five pictures of animals (dog, leopard, guinea pig, parrot, cat) and three examples of answers were offered: "The intruder may be the leopard because it is the only not tamed. But the intruder can also be the parrot because it is the only bird. Or the attacker can be the cat because it's the only one you have at home. Etc. There is no right or wrong answer. " As a result, each list was therefore presented on independent boards. Participants therefore realized this categorization task at first.

\section{Knowing task of sorting instructions}

To measure the level of knowledge of sorting instructions, the ten lists were they presented again this time instructed to appoint, in Lists A , the waste covered by the collection, and in lists B, the waste not covered by selective collection.

\section{Sorting practices self-reported}

Participants were asked on a Likert five-point scale on their practical sort of frequency : from zero (never) to five (always).

At the end of the questionnaire, participants were informed of their age, gender and city of residence.

All contract awards was conducted by three different investigators and to passersby on various public spaces. The study was presented as a triage test as part of a study in psychology. The experimenter presented each series one after the other and took note of the participant responses on the entry sheet. After the categorization task, participants responded on a form (A4) other questions.

\section{Results}

In total, 191 participants proposed 1907 waste classifications. In analyzing the results, formulated answers were grouped into six categories defined a priori. A seventh category includes answers that can incorporate any of the above categories:

The collection: there are in this category criteria for sorting and its instructions, such as "the only recyclable," "the one to throw in the yellow trash," etc.;

Material (s): This category includes responses from responses related to $(\mathrm{x})$ material $(\mathrm{s})$ of waste constitution, such as "the only metal", "paper", etc.;

Use: These answers referring to the usual function of the object before being waste. We have grouped in this category responses such as "the only hygiene product", "food only", etc.; 
Page 5 of 7

Shape: These criteria refer to the physical characteristics of the waste. The largest number of responses made its shape design with criteria such as "the only aerosol" or "bottle". It may also be his waist with answers such as "smaller" or other features as "hollow" or "dry";

The place: The answers referring to a location, basically use have been grouped in this category. It includes responses such as "in the bathroom", "outside", etc. ;

The theme we have grouped the answers referring to a thematic universe, imaginary or symbolic. We find answers such as "the one who does not think about Christmas," "cultural," etc. ;
Other: This last category of responses includes all the responses that could not incorporate any of the above categories. This is basically infrequent responses such as "the only expensive," "the best", etc.

The distribution in the different categories of participants' responses is presented in Table 2 .

\begin{tabular}{|l|l|l|l|l|l|l|l|l|l|l|l|}
\hline \multirow{2}{*}{ Listes } & Matériau & Forme & Usage & Lieu & Thème & \multicolumn{3}{|l|}{ Aléatoire } & \multicolumn{3}{l|}{ Total } \\
\cline { 2 - 12 } & $\mathbf{1}$ & $\mathbf{2}$ & $\mathbf{3}$ & $\mathbf{4}$ & $\mathbf{5}$ & $\mathbf{6}$ & $\mathbf{7}$ & $\mathbf{8}$ & $\mathbf{9}$ & $\mathbf{1 0}$ \\
\hline Collecte selective & $18(9 \%)$ & $23(12 \%)$ & $14(7 \%)$ & $6(3 \%)$ & $10(5 \%)$ & $8(4 \%)$ & $13(7 \%)$ & $29(15 \%)$ & $16(8 \%)$ & $12(6 \%)$ & $149(8 \%)$ \\
\hline Matériaux & $79(41 \%)$ & $4(2 \%)$ & $9(5 \%)$ & $16(8 \%)$ & $4(2 \%)$ & $27(14 \%)$ & $116(\%)$ & $79(41 \%)$ & $41(21 \%)$ & $5(3 \%)$ & $275(14 \%)$ \\
\hline Usage & $22(11 \%)$ & $43(22 \%)$ & $143(75 \%)$ & $99(52 \%)$ & $32(17 \%)$ & $88(46 \%)$ & $82(43 \%)$ & $13(7 \%)$ & $5529(\%)$ & $139(73 \%)$ & $716(37 \%)$ \\
\hline Forme & $35(18 \%)$ & $105(55 \%)$ & $6(3 \%)$ & $22(11 \%)$ & $5(3 \%)$ & $14(7 \%)$ & $33(17 \%)$ & $38(20 \%)$ & $51(27 \%)$ & $3(2 \%)$ & $312(19 \%)$ \\
\hline Lieu & $/$ & $/$ & $/$ & $35(18 \%)$ & $/$ & $3418(\%)$ & $35(18 \%)$ & $2(1 \%)$ & $/$ & $14(7 \%)$ & $120(6 \%)$ \\
\hline Thème & $/$ & $/$ & $/$ & $/$ & $128(67 \%)$ & $/$ & $4(2 \%)$ & $/$ & $6(3 \%)$ & $11(6 \%)$ & $149(7 \%)$ \\
\hline Autre & $37(20 \%)$ & $16(8 \%)$ & $19(10 \%)$ & $13(7 \%)$ & $12(6 \%)$ & $19(10 \%)$ & $11(6 \%)$ & $30(16 \%)$ & $22(12 \%)$ & $7(4 \%)$ & $186(9 \%)$ \\
\hline Total & 191 & 191 & 191 & 191 & 191 & 190 & 189 & 191 & 191 & 191 & 1907 \\
\hline
\end{tabular}

Table 2: Classification criteria for ten series.

All classification criteria have not been mobilized with the same frequency by participants $(\mathrm{Fr}=483.07,7, \mathrm{p}<0.001)$. One that was most often been used on all lists relates to the use of function of the object to throw (37\%) with a variation in function lists between $7 \%$ and $75 \%$ of the responses. Far behind, the collection has meanwhile been adopted as classification criterion to 149 times, which represents $8 \%$ of the responses. Depending lists, this number varies between 6 (3\%) and 29 (15\%). There is no difference between the number of classifications depending on the curbside between sets of List A and List $B(t=0.98,190, N S)$. This observation is valid for the number of categorization according to the use $(\mathrm{t}=2.22,190, \mathrm{HL})$ and the form $(\mathrm{t}$ $=2.59,190, \mathrm{NS})$, as well as the number of the other category responses $(t=0.97,190, N S)$. The number of categorization according to the material $(\mathrm{t}=-4.03,190, \mathrm{p}<0.001)$, the subject $(\mathrm{t}=15.28,190, \mathrm{p}<$ $0.001)$ and place $(\mathrm{t}=-4.33,190, \mathrm{p}<0.001)$ differ in them between the two series. Specifically, the location has frequently been mentioned on the series of List B on List A, while the opposite occurs for categorization according to the theme. Regarding the latter classification criterion, it is notable that answer basically is given by the participants to categorize the waste of the 5 series that we knowingly oriented in this direction. The very low frequency of occurrence of this criterion $(n=21)$ on all other series invites not to consider the subject area as a category often used by individuals to distinguish waste. We compared the frequency of occurrence of different categorization criteria and all of these results are presented in Table 3.

\begin{tabular}{|c|c|c|c|c|c|c|}
\hline Critères & Matériaux & Usage & Forme & Lieu & Thème & Autre \\
\hline Collecte sélective & $\mathrm{t}=-3.28,190, \mathrm{p}<.005$ & $\mathrm{t}=-12.32,190, \mathrm{p}<.001$ & $\mathrm{t}=-4.43,190, p<.001$ & $\mathrm{t}=.89,190, \mathrm{NS}$ & $t=-.13,190, N S$ & $\mathrm{t}=.20,190, \mathrm{NS}$ \\
\hline Matériaux & & $\mathrm{t}=12.26,190, \mathrm{p}<.001$ & $\mathrm{t}=-1.34,190, \mathrm{NS}$ & $t=6.10,190, p<.001$ & $\mathrm{t}=4.84,190, \mathrm{p}<.001$ & $\mathrm{t}=4.62,190, \mathrm{p}<.001$ \\
\hline Usage & & & $t=13.63,190, p<.001$ & $t=19.18,190, p<.001$ & $\mathrm{t}=20.99,190, p<.001$ & $\mathrm{t}=16.33,190, \mathrm{p}<.001$ \\
\hline Forme & & & & $t=9.86,190, p<.001$ & $\mathrm{t}=9.43,190, \mathrm{p}<.001$ & $\mathrm{t}=6.67,190, \mathrm{p}<.001$ \\
\hline Lieu & & & & & $t=-2.64,190, N S$ & $\mathrm{t}=.91,190, \mathrm{NS}$ \\
\hline Thème & & & & & & $\mathrm{t}=.49,190, \mathrm{NS}$ \\
\hline
\end{tabular}

Table 3: Pairwise comparison of the frequency of occurrence of the criteria on all series. 
Page 6 of 7

The pairwise comparisons confirm that the most common categorizations based on the use of functions of the fallen object. Indeed, this criterion for categorization is significantly more successful than other criteria. (S) material (s) design and shape of the waste are the criteria then appear in frequency. The collection, location and theme are less often chosen as a classification criterion.

Looking more specifically the proposed classifications based on the collection, shows that 55 participants said that test categorization at least once. Of these, 32 have made use of a recovery and 6 have mentioned to all lists. The retail distribution evocations of the collection as a classification criterion is presented in Table 4. Of the series A (defined a priori), the criterion of selective collection was selected 71 times and 16 participants who used at least once this categorization criteria. Of the series B (random), this criterion was mentioned 78 times by 51 participants who have used it at least once. As expected, there is a correlation between the mobilization of this criterion on the two series $(\mathrm{r}=.418, \mathrm{p}<.001)$. The analysis also shows that all participants have not mobilized the classification criteria with the same frequency $(\mathrm{Fr}=210.9,9, \mathrm{p}<.001)$.

We measured the level of understanding of sorting instructions using ten sets of five waste. Participants were asked to describe what each waste was the only recyclable or non-recyclable list. Results in knowledge of the test is presented in Table 4.

\begin{tabular}{|l|l|l|l|l|l|l|l|l|l|l|l|}
\hline $\begin{array}{l}\text { Nombre de bonnes } \\
\text { réponses }\end{array}$ & $\mathbf{1}$ & $\mathbf{2}$ & $\mathbf{3}$ & $\mathbf{4}$ & $\mathbf{5}$ & $\mathbf{6}$ & $\mathbf{7}$ & $\mathbf{8}$ & $\mathbf{9}$ & $\mathbf{1 0}$ \\
\hline Effectifs (N=191) & $9(5 \%)$ & $12(6 \%)$ & $23(12 \%)$ & $19(10 \%)$ & $36(19 \%)$ & $40(21 \%)$ & $22(11 \%)$ & $17(9 \%)$ & $9(5 \%)$ & $\begin{array}{l}4 \\
(2 \%)\end{array}$ \\
\hline Pourcentage cumulé & $5 \%$ & $11 \%$ & $23 \%$ & $33 \%$ & $52 \%$ & $73 \%$ & $84 \%$ & $93 \%$ & $98 \%$ & $100 \%$ \\
\hline
\end{tabular}

Table 4: Distribution of participants in the knowledge test of sorting instructions.

The total score of correct answers on the knowledge test is $1009 / 1910$, an average score of $5.28 / 10(\sigma=2.2)$. The minimum score is 1 and was obtained by 9 participants, the maximum score of 10 was by 4 participants and the median score obtained by 40 participants is 6 . The analysis shows that the level of knowledge of the instructions is positively correlated with the number of classifications based on the selective collection $(\mathrm{r}=0.478, \mathrm{p}<.001)$.

We also measured the self-reported frequency of sorting practice. The breakdown of participants is presented in Table 5 .

\begin{tabular}{|l|l|l|l|l|l|}
\hline Score & $\mathbf{1}$ & $\mathbf{2}$ & $\mathbf{3}$ & $\mathbf{4}$ & $\mathbf{5}$ \\
\hline Effectifs (N=191) & $9(5 \%)$ & $32(17 \%)$ & $21(11 \%)$ & $48(25 \%)$ & $\begin{array}{l}81 \\
(42 \%)\end{array}$ \\
\hline Pourcentage cumulé & $5 \%$ & $21 \%$ & $32 \%$ & $58 \%$ & $100 \%$ \\
\hline
\end{tabular}

Table 5: Fréquence de tri auto-déclarée.

On a Likert five-point scale, with 1 for zero and 5 practical for routine practice, the average response of the participants was $3.84(\sigma=$ 1.27). The frequency of the practice of sorting is positively correlated with the level of knowledge $(r=0.366, p<0.001)$ and with the number of categorizations based on the criterion of selective collection $(\mathrm{r}=$ $0.215, \mathrm{p}<0.001)$.

\section{Discussion and Conclusion}

The results show that the categorization of waste according to recycling instructions do not obvious. On the contrary, other categorizations appear much more frequently. The function of use of the fallen object, design or shape of the waste materials are the criteria most often applied by individuals to distinguish and classify waste. With privileged as classification criterion the use of function of the object, it seems that the perception of the object can even supplant that of the waste. However, alternative categorizations to those built on the criterion of the collection is likely to harm the quality of sorting performed. The individual captures only some of the countless ways to group and distinguish the elements and each time the categorization process is exclusive. Also, a categorization according to use or form exclude categorization by sorting instructions. It is to the detriment of the later that are perceived alternative categories. In addition, the categories formed the basis of criteria other than sorting instructions induce perceived similarities between the different elements together in one category. The sorting decision when to throw its waste can be affected by these perceived similarities. If an individual perceives similarities between waste and moreover if the fact coexist in the same category, is likely to attribute the characteristics of one another.

This is particularly the case plastic waste that share certain characteristics, including primarily the design of material, and that so far are not all covered by selective collection. The similarities between these perceived waste may however foster the allocation of other common characteristics, including instructions similar sort. The categorization process as "building the world" [5] can thus serve the waste management policy, as it will not take into account. Also, with a sorting centers park dating back more than 10 years on average [1], redevelopment of it proves necessary to absorb the additional tonnage and can present the opportunity to enhance the technological advances in automated sorting one hand, and to homogenize the instructions along with their technical devices. This harmonization would deploy national information systems. Signaling an appropriate sort of behavior logo can not be considered as the instructions will not be harmonized. This can be recognized as particularly regrettable that signage often shows an appropriate and successful adaptation to the inherent need of the individual to categorize itemsn [36-39].

\section{References}

1. Eco-Emballages (2012) Eco-Emballages, 20 ans de tri et de recyclage, Dossier de presse de décembre 2012.

2. Eco-Emballages (2010) Plan national du tri et du recyclage d'EcoEmballages et d'Adelphe, Dossier de presse du 30 juin 2010.

3. Panafit L (2002) Les déchets, un bien public, un mal privé.

4. Bruner J, Goodnow JJ, et Austin GA (1960) A Study of Thinking. John Wiley, New York. 
Page 7 of 7

5. Chandler D (1997) Visual Perception: Context and Expectations, Categorization and Selectivity.

6. Allport GW (1954) The Nature of Prejudice. Reading, Addison-Wesley.

7. Allport GW (1960) Personality and social encounter: Selected essays. Boston, Beacon Press.

8. Barsalou LW (1999) Perceptual symbol systems. Behav Brain Sci 22: 577-609.

9. Barsalou LW (1989) Intraconcept similarity and its implications for interconcept similarity.

10. Hahn U, et Ramscar MJA (2001) Mere similarity?.

11. Rosch E, et Mervis CB (1975) Family Resemblances: Studies in the Internal Structure of Categories. Cognitive Psychology 7: 573-605.

12. Hampton JA (2000) Concepts and Prototypes. Mind and Language 15: 299-307.

13. Medin DL, et Schaffer MM (1978) Context theory of classification learning. Psychological Review 85: 207-238.

14. Medin DL, et Ortony A (1989) Psychological essentialism.

15. McClelland JL, et Rumelhart DE (1985) Distributed memory and the representation of general and specific information. Journal of Experimental Psychology: General 114: 159-188.

16. Chrea C, Valentin D, Sulmont-Rossé C, Hoang Nguyen D, et Abdi H (2005) Semantic, typicality and odour representation : a cross-cultura study. Chemical Senses 30: 37-49.

17. Rosch E (1976) Classifications dobjets dans le monde réel : Origines et représentations dans la cognition. Bulletin de Psychologie, numéro spécial 21: 242-250.

18. Richard JF (2004) Les activités mentales. Paris, Armand Colin.

19. Barsalou LW (1982) Context-independent and context-dependent information in concepts. Memory \& Cognition 10: 82-93.

20. Barsalou LW, Huttenlocher J, et Lamberts K (1998) Basing categorization on individuals and events. Cogn Psychol 36: 203-272.

21. Murphy GL (2002) Conceptual approaches I: An overview.

22. Vosniadou S, et Brewer WF (1992) Mental models of the earth: A study of conceptual change in childhood. Cognitive Psychology 24: 535-585.

23. Mazens K, et Lautrey J (2003) Conceptual change in physics : children's naïve representations of sound. Cognitive Development 18: 159-176.
24. Rosch E (1978) Principles of categorization.

25. Rehder B, et Kim S (2010) Causal status and coherence in causal-based categorization. J Exp Psychol Learn Mem Cogn 36: 1171-1206.

26. Poitrenaud S, Richard JF, et Tijus C (2005) Properties, categories and categorization. Thinking and Reasoning 11: 151-120.

27. Gaillard A, et Urdapilleta I (2013) Représentations mentales et catégorisation : théories et méthodes.

28. Loken B, Barsalou LW, et Joiner C (2008) Categorization theory and research in consumer psychology: Category representation and categorybased inference.

29. Urdapilleta I (2001) Introduction générale.

30. Urdapilleta I (2007) Représentations alimentaires et sensorielles: une approche par la catégorisation. Habilitation à Diriger des Recherches, Université Paris VIII, Paris.

31. Medin DL, Lynch EB, Coley JD, et Atran S (1997) Categorization and reasoning among tree experts: Do all roads lead to Rome ?. Cognitive Psychology 32: 49-96.

32. Chemlal S, et Cordier F (2006) Structures conceptuelles, représentation des objets et des relations entre les objets. Canadian Journal of Experimental Psychology 60: 7-23.

33. Bonthoux F, et Kalénine S (2007) Preschoolers' superordinate taxonomic categorization as a function of individual processing of visual vs. contextual/functional information and object domain. Cognition, Brain \& Behavior, Special Issue on the Development of Categorization 11 : 713-731.

34. Bloom P (1998) Theories of artefact categorization. Cognition 66 : 87-93.

35. Barton ME, et Komatsu LK (1989) Definig features of natural kinds and artifacts. Journal of Psycholinguistic Research 18: 433-447.

36. http://www.aber.ac.uk/media/Modules/TF12710/visper05.html .

37. Goldstone RL (1994) The role of similarity in categorization: Providing a groundwork. Cognition 52: 125-157.

38. Lakoff G (1987) Women, Fire, and Dangerous Things: What Categories Reveal about the Mind. The University of Chicago Press.

39. Medin DL (1989) Concepts and conceptual structure. Am Psychol 44: 1469-1481. 